\title{
Radical change in osteosarcoma surgical plan due to COVID-19 pandemic
}

\author{
Czar Louie Lopez Gaston, ${ }^{1,2}$ Johann Proceso Pag-ong, ${ }^{1}$ Emilleo Dacanay, ${ }^{2}$ \\ Albert Jerome Quintos ${ }^{2}$
}

'Department of Orthopedics, Quirino Memorial Medical Center, Quezon City, Philippines 2Department of Orthopedics, College of Medicine and Philippine General Hospital, University of the Philippines Manila, Manila, Philippines

Correspondence to Dr Czar Louie Lopez Gaston; clgaston@up.edu.ph

Accepted 28 June 2020

Check for updates

(c) BMJ Publishing Group Limited 2020. No commercial re-use. See rights and permissions. Published by BMJ.

To cite: Gaston $\mathrm{CL}$

Pag-ong JP, Dacanay E,

et al. BMJ Case Rep

2020:13:e237197.

doi:10.1136/bcr-2020-

237197

\section{SUMMARY}

A 17-year-old man with osteosarcoma of the proximal humerus was planned for possible limb salvage surgery after standard neoadjuvant chemotherapy. However, during the surgical phase of treatment, the COVID-19 or SARS-CoV-2 (severe acute respiratory syndrome coronavirus 2) outbreak occurred changing the healthcare landscape due to uncertainty regarding the virus, risk of COVID-19 infection and complications, and implementation of an enhanced community quarantine restricting movement of people within cities. Instead of limb salvage surgery, the patient underwent a forequarter amputation. Exposure to the virus in a high-risk hospital setting was minimised with patient discharge after a short hospital stay and home convalescence monitored by video conferencing. Multidisciplinary sarcoma team meetings with family members and a sarcoma navigator nurse were crucial in managing expectations and deciding on appropriate treatment in the setting of a novel infectious disease causing a pandemic.

\section{BACKGROUND}

Osteosarcoma is a rare primary bone malignancy that commonly affects children, adolescents and young adults. Treatment consists of a combination of chemotherapy and surgery and is best delivered by a dedicated sarcoma team in a multidisciplinary setting. ${ }^{12}$ Limb salvage surgery, where the tumour is completely resected and the resulting bone defect reconstructed, has become the standard surgical option whenever clear surgical margins around the tumour is obtainable while preserving the important anatomical structures critical for limb function. Amputations are still performed in large, extensive tumours, which have not responded to neoadjuvant chemotherapy but are associated with poorer function than limb salvage surgery and have low acceptance with patients and their families. ${ }^{3-5}$ Close coordination between the different subspecialities of the sarcoma team and the family and adherence to various treatment schedules is important for good outcomes.

In January 2020, an outbreak of pneumonia caused by a novel coronavirus was first reported in China. Initially transmitted by persons with a history of travel to affected countries, COVID-19 was declared a pandemic in March 2020 due to its spread into communities worldwide. ${ }^{6}$ Whole countries and economies ground to a halt as community lockdowns and quarantines were ordered to prevent the spread of the virus. ${ }^{7}$ Protocols for everyday life changed overnight from work-from-home arrangements to limited public transportation. As hospitals and healthcare workers throughout were placed under enormous pressures due to the numbers of infected individuals, healthcare systems adapted as well. In some hospitals, admissions and elective surgeries for non-COVID-19 cases were suspended to allow for surges of COVID-19 patients and avoid exposure of uninfected individuals. ${ }^{8}$ We report on an otherwise uncomplicated case of osteosarcoma whose surgical plan changed radically during the early stages of the COVID-19 pandemic.

\section{CASE PRESENTATION}

A 17-year-old man, right-hand dominant, presented at our institution in November 2019 with pain and swelling of the left shoulder. Plain radiographs showed an expansile, osteoblastic lesion of the proximal humerus typical for osteosarcoma. Diagnosis was confirmed by core needle biopsy and after completion of staging studies, which did not reveal any signs of systemic spread, he underwent neoadjuvant chemotherapy with doxorubicin and cisplatin. There was note of a good clinical response and after three cycles of chemotherapy, an MRI scan in March 2020 showed a large, heterogeneously enhancing mass arising from the proximal humerus metaphysis (figure 1). The main neurovascular bundle, including the brachial artery and median and ulnar nerves, was clear of the tumour. Given the proximal soft tissue tumour extent around the glenoid, the initial surgical plan was for an extra-articular resection of the proximal humerus and glenoid (Malawer type VB). ${ }^{9}$ However, a few days later, an enhanced community quarantine was ordered in the Philippines due to the novel COVID-19/SARS-CoV-2 (severe acute respiratory syndrome coronavirus 2) pandemic.

Due to early reports regarding patients and healthcare workers safety during the COVID-19 pandemic, ${ }^{10-14}$ multidisciplinary sarcoma team and family meetings were undertaken by videoconference to decide on the treatment plan for the patient with the main considerations being (1) patient's risk for contracting COVID-19 while undergoing hospital treatment (chemotherapy or surgery), (2) patient's risk of developing complications if infected with COVID-19 and (3) healthcare institution's capacity to provide safe and effective treatment. 


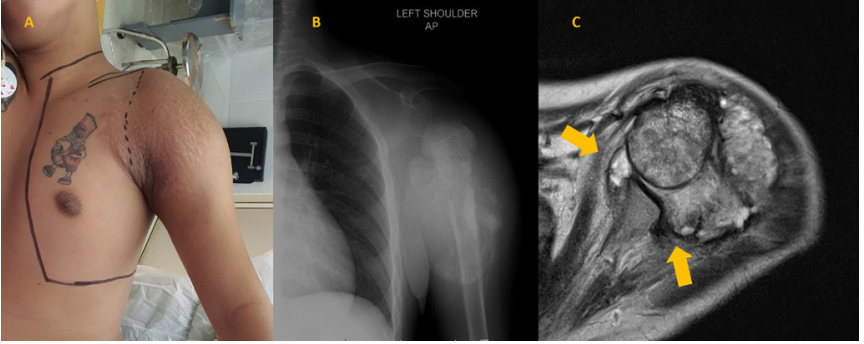

Figure 1 (A, B) Osteosarcoma of the proximal humerus with typical osteoblastic matrix on plain AP (antero-posterior) radiographs. (C) Axial T1 MRI image of the shoulder showing extent of tumour around the glenoid (arrows).

The treatment options discussed included (a) continuing with neoadjuvant chemotherapy, (b) limb salvage surgery or (c) forequarter amputation. Being admitted in hospital for either another cycle of neoadjuvant chemotherapy or surgery would risk the patient being exposed to COVID-19 and so the decision was to proceed with surgery for local control based on the timing of his osteosarcoma treatment. ${ }^{12}$ Limb salvage surgery and corresponding reconstruction would entail a longer hospital stay risking more exposure to the virus. Complex reconstructive surgery would require prolonged monitoring and problems with postoperative follow-up under an enhanced community quarantine, where movement and transportation outside of individual households were restricted by the government, were anticipated. The surgical team (CLLG and JPP-o) also relayed their previous difficulties in performing surgery with enhanced personal protection equipment (PPE) in the form of heat stress and poor face mask visibility. After thorough discussion with the family, an amputation was decided on.

The surgery was performed in a tertiary government hospital catering to both patients with COVID-19 and patients without COVID-19. At the time, Reverse Transcriptase-PCR testing for COVID-19 was limited and not done routinely for asymptomatic patients with normal chest radiographs. A forequarter amputation was performed under general anaesthetic. All members of the surgical team wore Tyvek overalls (Dupont, USA), N95 respirators (3M, USA) and face masks in addition to the standard surgical gowns and gloves (figure 2). The operation lasted $100 \mathrm{~min}$ from induction to subcuticular skin closure

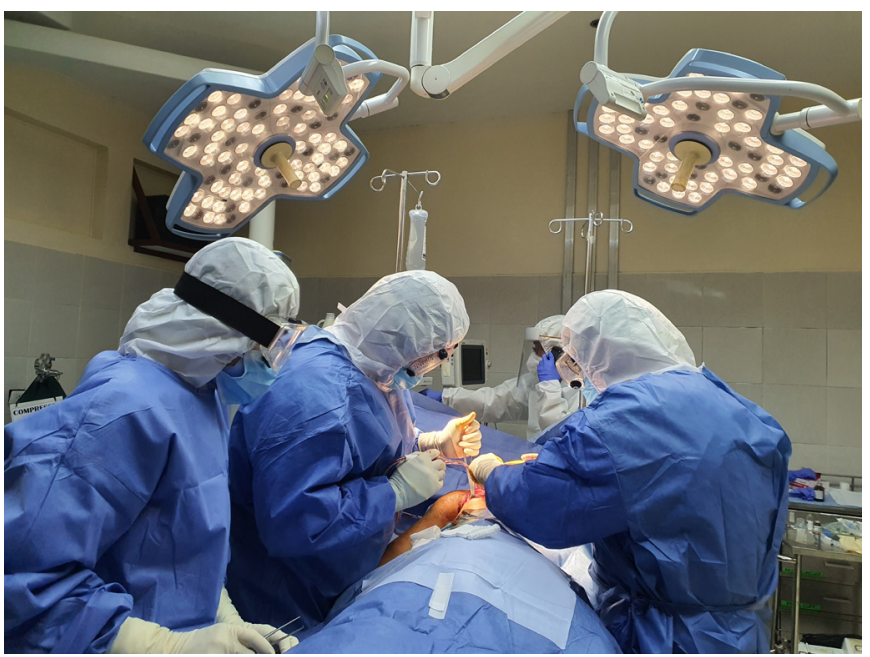

Figure 2 Forequarter amputation undertaken using enhanced personal protective equipment.

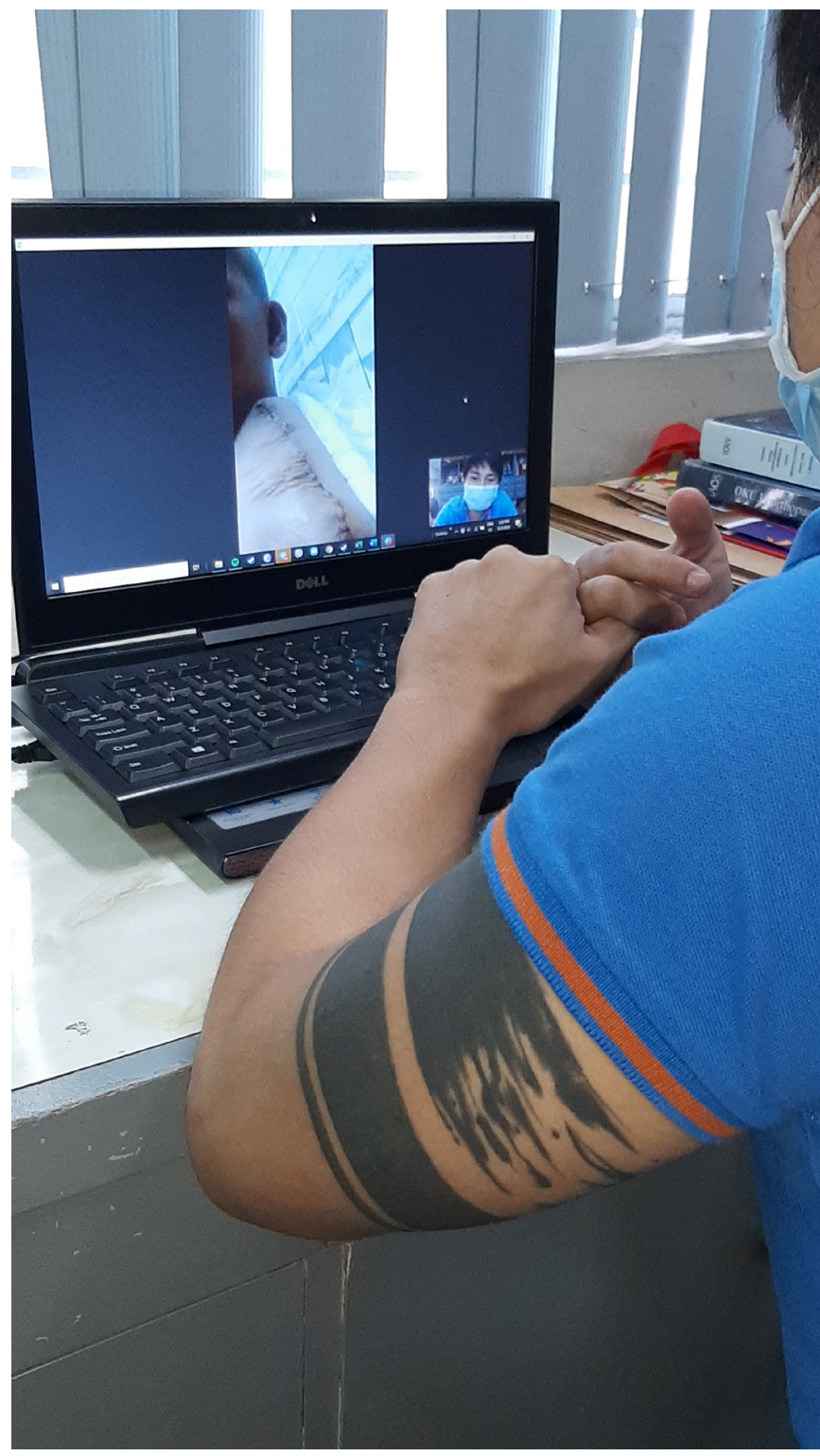

Figure 3 Postoperative recovery and wound inspection by video conferencing.

with absorbable sutures with estimated blood loss of $400 \mathrm{cc}$. No complications were noted intraoperatively and the patient was discharged well on the second postoperative day.

\section{OUTCOME AND FOLLOW-UP}

The patient recovered satisfactorily at home and wound healing was monitored by video conferencing to avoid hospital attendance (figure 3). Histopathological examination of the amputation specimen confirmed a high-grade osteosarcoma with tumor-free bone and soft tissue surgical margins. Throughout the treatment process above, the patient and his family did not exhibit signs and symptoms related to COVID-19 infection. The patient is currently awaiting hospital admission for continuation of adjuvant chemotherapy.

\section{DISCUSSION}

The COVID-19/SARS-CoV-2 pandemic has disrupted multiple aspects of daily life for many nations around the world. In healthcare, intense focus and resources have been diverted to treating 
COVID-19 patients and stemming the tide of infections, sometimes to the detriment of non-COVID-19 health conditions. ${ }^{14}$ Early reports found that cancer patients were especially vulnerable to COVID-19 and had higher mortality. ${ }^{11}{ }^{12}$ Precautions such as delaying surgery for stable tumours, changing chemotherapy timing and schedule, and avoiding frequent hospital visits were initial recommendations to avoid viral nosocomial infection for cancer patients in general. ${ }^{15-17}$

There have been few reports to guide treatment of sarcoma patients during the time of COVID-19, both published in April, well into the pandemic, and were not available during our multidisciplinary discussions. The French Sarcoma Group and Drs Cardoso and Rodrigues-Pinto wrote recommendations for the general treatment of sarcomas during COVID-19 outbreak. ${ }^{18} 19$ Both underscored the need for continued treatment of osteosarcomas and that surgery for those patients having had neoadjuvant chemotherapy should be prioritised. Their reasoning to avoid delays that could compromise curative outcomes was in keeping with the treatment approach taken in our patient.

The main dilemma in our case was the change in surgical plan from limb salvage surgery to a proximal limb amputation. Up to the time of writing, there have been no studies regarding the safety of limb salvage surgery during this viral outbreak. The primary consideration taken into this decision was the risk of contracting nosocomial COVID-19 if the osteosarcoma patient underwent limb salvage versus an amputation. The initially planned limb salvage procedure for our patient was an extraarticular resection of the proximal humerus and reconstruction with a bone cement prosthesis, ${ }^{2021}$ which would have required longer operative time, longer hospital stay and repeated follow-up as compared with a forequarter amputation. At the time of multidisciplinary family discussions, longer exposure to the hospital

\section{Patient's perspective}

When my doctors talked to me about having an amputation, I did not want to have it at first because I am scared of bullying. They had previously told me that my chemotherapy was working and that my arm would likely be saved. However, their plans changed when COVID-19 arrived. It took a long time before my mother and I decided to go for the surgery.

Now that I have had the amputation, I am happy with my decision. I look forward to complete my chemotherapy and to have a prosthesis fitted.

Learning points

- COVID-19/SARS-CoV-2 (severe acute respiratory syndrome coronavirus 2) pandemic has changed healthcare systems thereby affecting treatment protocols for non-COVID-19 conditions, including cancer.

- Osteosarcoma patients require multiple treatment modalities that need to be re-tailored individually to avoid nosocomial infection from prolonged hospital exposure.

- Multidisciplinary sarcoma team meetings with family members are crucial for deciding treatment in the deficiency of clear medical evidence in a pandemic.

- Better understanding of the COVID-19/SARS-CoV-2 pandemic, adequate testing and screening for infection, and appropriate personal protection equipment usage may enable complex limb salvage surgery to be done safely. environment was thought to have a higher risk of developing COVID-19. Current reports have since confirmed this as well as the complications associated with nosocomial COVID-19 infection. $^{22}{ }^{23}$ Luong-Nguyen et al reported a $4.9 \%$ nosocomial infection rate for patients admitted for a gastric surgery with all patients developing at least one postoperative complication. ${ }^{22}$ Aside from adequate hygiene and personal protective equipment (PPE) use, they recommended reducing hospital stay to avoid viral exposure. Having dedicated COVID-19 negative centres with good screening procedures for elective surgery is another option to decrease risk of patient contamination. ${ }^{24}$ Other precautions taken for our patient to avoid exposure included home recovery and telemedicine consult, which have become popular during this pandemic. ${ }^{2425}$

The difficulty in performing surgery safely while using PPEs has been previously documented. ${ }^{25-27}$ Day et al describe how enhanced PPE may change the surgical plan and approach in treating head and neck cancers. ${ }^{25}$ Heat stress and face mask visibility were PPE issues previously experienced by the surgical team and this also affected the decision against complex limb salvage surgery. To address this, some authors recommend using ventilated powered air-purifying respirators if undertaking long surgical procedures but these are costly and not widely available. ${ }^{28}$ As the response to COVID-19 improves, greater RT-PCR testing capability can help stratify patients, and for asymptomatic low-risk patients, complex surgery can be safely performed using less intrusive PPE.

Acknowledgements We would like to acknowledge the core members of the Sarcoma MDT of the Philippine General Hospital involved in the multidisciplinary care of this patient (Patricia Alcasabas MD, Jenny Atun MD, Joie Canal MD, Henri Co MD, Cesar Dimayuga MD, Jochris Estanislao MD, Pam Fajardo MD, Gracieux Fernando MD, Czar Louie Gaston MD, Jenna Gonzales RN, Eugene Odonio MD, Albert Quintos MD, Donnel Rubio MD and Edward Wang MD).

Contributors CLLG conceptualised report, gathered data, wrote primary manuscript and reviewed the final manuscript. JPP-o gathered data and reviewed the final manuscript. ED gathered data and reviewed the final manuscript. AJQ conceptualised report and reviewed the final manuscript.

Funding The authors have not declared a specific grant for this research from any funding agency in the public, commercial or not-for-profit sectors.

Competing interests None declared.

Patient consent for publication Parental/guardian consent obtained.

Provenance and peer review Not commissioned; externally peer reviewed.

This article is made freely available for use in accordance with BMJ's website terms and conditions for the duration of the covid-19 pandemic or until otherwise determined by BMJ. You may use, download and print the article for any lawful, non-commercial purpose (including text and data mining) provided that all copyright notices and trade marks are retained.

\section{REFERENCES}

1 Isakoff MS, Bielack SS, Meltzer P, et al. Osteosarcoma: current treatment and a collaborative pathway to success. J Clin Oncol 2015;33:3029-35.

2 Senerchia AA, Macedo CR, Ferman S, et al. Results of a randomized, prospective clinical trial evaluating metronomic chemotherapy in nonmetastatic patients with high-grade, operable osteosarcomas of the extremities: a report from the Latin American group of osteosarcoma treatment. Cancer 2017;123:1003-10.

3 Han G, Bi W-Z, Xu M, et al. Amputation versus Limb-Salvage surgery in patients with osteosarcoma: a meta-analysis. World J Surg 2016;40:2016-27.

4 Friedrich $\mathrm{P}$, Ortiz R, Strait K, et al. Pediatric sarcoma in central America: outcomes, challenges, and plans for improvement. Cancer 2013;119:871-9.

5 Kamal AF, Widyawarman $\mathrm{H}$, Husodo $\mathrm{K}$, et al. Clinical outcome and survival of osteosarcoma patients in Cipto Mangunkusumo Hospital: limb salvage surgery versus amputation. Acta Med Indones 2016;48:175-83.

6 WHO. Coronavirus disease (COVID-19) situation report 3. Philippines 12 March 2020. Available: https://www.who.int/docs/default-source/wpro-documents/countries/ philippines/emergencies/covid-19/who-phl-sitrep-3-covid-19-12mar2020.pdf; [Accessed 22 May 2020]. 


\section{Novel treatment (new drug/intervention; established drug/procedure in new situation)}

7 WHO. Coronavirus disease (COVID-19) situation report 4. Philippines 14 March 2020 Available: https://www.who.int/docs/default-source/wpro-documents/countries/ philippines/emergencies/covid-19/who-phl-sitrep-4-covid-19-14mar2020.pdf; [Accessed 22 May 2020].

8 Department of Health Interim Guidelines on COVID-19 Referral Hospitals. Philippines 23 March 2020. Available: https://www.doh.gov.ph/sites/default/files/health-update/ dm2020-0142.pdf; [Accessed 22 May 2020].

9 Malawer MM. Tumors of the shoulder girdle. technique of resection and description of a surgical classification. Orthop Clin North Am 1991;22:7-35.

10 Bai Y, Yao L, Wei T, et al. Presumed asymptomatic carrier transmission of COVID-19. JAMA 2020;323:1406-7.

11 Liang W, Guan W, Chen R, et al. Cancer patients in SARS-CoV-2 infection: a nationwide analysis in China. Lancet Oncol 2020;21:335-7.

12 Yu J, Ouyang W, Chua MLK, et al. SARS-CoV-2 transmission in patients with cancer at a tertiary care hospital in Wuhan, China. JAMA Oncol 2020;25:e200980.

13 Shankar A, Saini D, Roy S, et al. Cancer Care Delivery Challenges Amidst Coronavirus Disease - 19 (COVID-19) Outbreak: Specific Precautions for Cancer Patients and Cancer Care Providers to Prevent Spread. Asian Pac J Cancer Prev 2020;21:569-73.

14 Wang H, Zhang L. Risk of COVID-19 for patients with cancer. Lancet Oncol 2020;21:e181.

15 Al-Shamsi HO, Alhazzani W, Alhuraiji A, et al. A practical approach to the management of cancer patients during the novel coronavirus disease 2019 (COVID-19) pandemic: an international Collaborative group. Oncologist 2020;25:e936-45.

16 Lindeman R-J, Sund M, Löfgren J, et al. Preventing spread of SARS-CoV-2 and preparing for the COVID-19 outbreak in the surgical department: perspectives from two Scandinavian countries. J Surg Case Rep 2020;2020:rjaa131. eCollection 2020.

17 Chaves ALF, Castro AF, Marta GN, et al. Emergency changes in international guidelines on treatment for head and neck cancer patients during the COVID-19 pandemic. Oral Oncol 2020;107:104734.

18 Penel N, Bonvalot S, Minard V, et al. French sarcoma group proposals for management of sarcoma patients during the COVID-19 outbreak. Ann Oncol 2020;9.
19 Cardoso P, Rodrigues-Pinto R. Surgical management of bone and soft tissue sarcomas and skeletal metastases during the COVID-19 pandemic. Eur J Surg Oncol 2020;46:1178-9.

20 Kundu ZS, Gogna P, Gupta V, et al. Proximal humeral reconstruction using nail cement spacer in primary and metastatic tumours of proximal humerus. Strategies Trauma Limb Reconstr 2013:8:149-54.

21 Rafalla AA, Abdullah ESA. Endoprosthetic replacement versus cement spacer in reconstruction of proximal humerus after tumor resection: cost and benefits. J Orthop Surg 2017;25:230949901771393.

22 Luong-Nguyen M, Hermand $\mathrm{H}$, Abdalla S, et al. Nosocomial infection with SARS-Cov-2 within departments of digestive surgery. J Visc Surg 2020;Apr 27:S1878-7886:30122-3.

23 Li Y-K, Peng S, Li L-Q, et al. Clinical and Transmission Characteristics of Covid-19 - A Retrospective Study of 25 Cases from a Single Thoracic Surgery Department. Curr Med Sci 2020;40:295-300.

24 Massey PA, McClary K, Zhang AS, et al. Orthopaedic surgical selection and inpatient paradigms during the coronavirus (COVID-19) pandemic. J Am Acad Orthop Surg 2020:28:436-50.

25 Day AT, Sher DJ, Lee RC, et al. Head and neck oncology during the COVID-19 pandemic: reconsidering traditional treatment paradigms in light of new surgical and other multilevel risks. Oral Oncol 2020;105:104684.

26 Loibner M, Hagauer S, Schwantzer G, et al. Limiting factors for wearing personal protective equipment (PPE) in a health care environment evaluated in a randomised study. PLoS One 2019;14:e0210775.

27 Greenland KB, Tsui D, Goodyear P, et al. Personal protection equipment for biological hazards: does it affect tracheal intubation performance? Resuscitation 2007:74:119-26

28 Hirschmann MT, Hart A, Henckel J, et al. COVID-19 coronavirus: recommended personal protective equipment for the orthopaedic and trauma surgeon. Knee Surg Sports Traumatol Arthrosc 2020;28:1690-8.

Copyright 2020 BMJ Publishing Group. All rights reserved. For permission to reuse any of this content visit https://www.bmj.com/company/products-services/rights-and-licensing/permissions/ BMJ Case Report Fellows may re-use this article for personal use and teaching without any further permission.

Become a Fellow of BMJ Case Reports today and you can

- Submit as many cases as you like

- Enjoy fast sympathetic peer review and rapid publication of accepted articles

- Access all the published articles

Re-use any of the published material for personal use and teaching without further permission

Customer Service

If you have any further queries about your subscription, please contact our customer services team on +44 (0) 2071111105 or via email at support@bmj.com.

Visit casereports.bmj.com for more articles like this and to become a Fellow 